\title{
Day case ligation of patent ductus arteriosus in preterm infants: a 10 year review
}

\author{
Christopher R M Satur, Duncan R Walker, David F Dickinson
}

\begin{abstract}
Since 1978, 136 preterm babies received ligation of a patent ductus arteriosus as day cases. A total of 122 babies whose notes were available for review, with a median gestational age of 27 weeks (range 23-35) and median birth weight of $960 \mathrm{~g}$ (range 470-2750), were transported distances of up to 80 miles. The median ages at ligation with and without previous medical management with indomethacin were 23 and 15 days, respectively. One hundred and ten ( $90 \%$ ) babies were dependent on ventilatory support, but extubation was achieved at a median time of 10 days after ligation, regardless of postnatal age at the time of ligation. There were no deaths associated with the operation, and no complications resulting from transportation. The hospital mortality was $15(12 \cdot 3 \%)$, and the most important (and significant) adverse factor was a preoperative fractional inspiratory oxygen content greater than $\mathbf{0 . 3}$. The results of this study show that day case ligation of the patent ductus arteriosus is safe, and if it is carried out early will reduce the time before extubation and discharge from the intensive care unit.
\end{abstract}

The ductus arteriosus persists in $20 \%-30 \%$ of infants who are born weighing less than $2000 \mathrm{~g}$, and causes appreciable morbidity in many. ${ }^{1-3}$ The resultant respiratory failure may require prolonged ventilatory support, and is associated with increased mortality. The morbidity can, however, be reduced by early closure of the duct. $^{4}$

Indomethacin is usually the first line of treatment; if this fails ligation of the duct may be considered, but the practical details vary considerably among individual neonatal units. Ducts may be ligated in the incubator in the neonatal unit, or in an operating theatre of the same hospital. ${ }^{56}$ This, however, requires that a cardiothoracic surgeon has to travel what may be a long distance to and from the neonatal unit, which is not a cost effective use of his time. There has been a single report of neonates undergoing duct ligation as a day case. ${ }^{7}$

It has been our practice to have each baby transported from the referring neonatal unit to this supraregional cardiothoracic centre for duct ligation. The infants were then transported back to their units immediately after the procedure. In this study we report our 10 year experience of day case duct ligation, with reference to the related medical management.
Patients and methods

Between November 1978 and May 1989, 136 preterm infants with isolated patent ductus arteriosus were admitted for ligation, 119 as day cases; 122 patient records were available and have been reviewed. The median gestational age was 27 weeks (range 23-35) and the median birth weight $960 \mathrm{~g}$ (range 470-2750, 116 of whom weighed less than $1500 \mathrm{~g}$ ). Three regional neonatal units referred three quarters of the patients. A number of district general neonatal units collectively referred the remainder. Two of the regional neonatal units are in Leeds, and one is in Sheffield (35 miles away). The district hospitals were scattered throughout Yorkshire and North Trent.

The patent ductus arteriosus was diagnosed and treated in accordance with the medical protocol preferred locally. If these measures failed, ligation was requested. Before ligation the diagnosis was confirmed by a paediatric cardiologist using cross sectional cardiac ultrasonography. Particular care was taken to ensure that it was an isolated problem, and that it was of a size that was likely to be haemodynamically and clinically important.

Ligation of the duct was usually arranged at a day's notice. The responsibilities of the referring medical team were sending one unit of cross matched blood, obtaining parental consent, and providing an experienced nurse and medical escort for the infant. On arrival at this hospital, which was timed to coincide with a space in the routine operating list, the infant was transferred to the operating theatre.

A posterolateral thoracotomy was made through the fourth intercostal space, and the duct ligated with a single $2 / 0$ Persalls suture. The procedure required careful retraction with minimal compression of the lung, to provide good visibility of the operative field while maintaining ventilation of both lungs; we find the Killingbeck paediatric lung retrator indispensible. ${ }^{8}$ Chest drainage was not used routinely, but the lungs were fully inflated before the chest cavity was closed.

Demographic statistics and details of medical management before and after operation were recorded, as were the complications, and details of progress after ligation.

The data were not normally distributed, and so non-parametric tests (Mann-Whitney $U$, Spearman rank correlation, and $\chi^{2}$ tests) were used for analysis. A probability of $<0.05$ was accepted as significant.

Results

The various subgroups were comparable (table 
Table 1 Clinical details of infants treated by duct ligation after medical treatment. Figures expressed as median (range) except where otherwise stated

\begin{tabular}{|c|c|c|c|c|c|c|c|c|}
\hline \multirow{3}{*}{$\begin{array}{l}\text { Treatment } \\
\text { group }\end{array}$} & \multirow{3}{*}{$\begin{array}{l}\text { No of } \\
\text { infants }\end{array}$} & \multirow{3}{*}{$\begin{array}{l}\text { Gestation } \\
\text { (weeks) }\end{array}$} & \multirow{3}{*}{$\begin{array}{l}\text { Birth } \\
\text { weight } \\
\text { (g) }\end{array}$} & \multirow{3}{*}{$\begin{array}{l}\text { Age at } \\
\text { diagnosis } \\
\text { (days) }\end{array}$} & \multicolumn{4}{|c|}{ Age at ligation (days) after medical treatment } \\
\hline & & & & & \multicolumn{2}{|c|}{ Without indomethacin } & \multicolumn{2}{|c|}{ With indomethacin } \\
\hline & & & & & $\begin{array}{l}\text { No of } \\
\text { infants }\end{array}$ & $\begin{array}{l}\text { Median } \\
\text { (range) }\end{array}$ & $\begin{array}{l}\text { No of } \\
\text { infants }\end{array}$ & $\begin{array}{l}\text { Median } \\
\text { (range) }\end{array}$ \\
\hline \multirow{4}{*}{$\begin{array}{l}\text { Regional neonatal } \\
\text { unit A } \\
\text { Regional neonatal } \\
\text { unit B } \\
\text { Regional neonatal } \\
\text { unit C } \\
\text { District general } \\
\text { hospitals (D) }\end{array}$} & 30 & $28(24-34)$ & $1020(620-2750)$ & 5 & 25 & $16(5-63)$ & 5 & $13(3-17)$ \\
\hline & 32 & $27(23-33)$ & $1000(470-2330)$ & 5 & 16 & $13 \cdot 5(6-25)$ & 16 & $22 \cdot 5(10-42)$ \\
\hline & 31 & $27(23-35)$ & $940(550-1550)$ & 6 & 21 & $21(7-44)$ & 10 & $23(16-36)$ \\
\hline & 29 & $26(23-34)$ & $920(680-2340)$ & 7 & 7 & $15(5-39)$ & 22 & $26(9-48)$ \\
\hline Total & 122 & $27(23-35)$ & $960(470-2750)$ & 6 & 69 & $15(5-63)$ & 53 & $23(3-48)$ \\
\hline
\end{tabular}

1). The median ages at the time of clinical diagnosis of the patient ductus were also similar (roughly 6 days). Of the 122 infants reviewed, $53 \mathrm{had}$ received indomethacin before referral for duct ligation (table 1). Ducts were ligated significantly earlier in patients who did not receive indomethacin $(\mathrm{p}<0.001)$.

All hospitals practised some degree of fluid restriction before ligation, but it was possible to withdraw restrictions within five days of operation (table 2). Mechanical ventilation was required by 110 infants $(90 \%)$ with a median fractional inspired oxygen concentration $\left(\mathrm{F}_{1} \mathrm{O}_{2}\right)$ of 0.3 before ligation (table 3 ). Infants of less than 26 weeks' gestation (43\%) or weighing less than $1000 \mathrm{~g}$ at birth (51\%) were ventilated longer (median 15 and 14 days, respectively) than the older and larger infants (median 8 and 6 days) after ligation $(\mathrm{p}<0.01)$. The $\mathrm{F}_{\mathrm{I}} \mathrm{O}_{2}$ given on the day after ligation was temporarily higher,

Table 2 Policies of fluid restriction practised in infants with patent ductus arteriosus. Values are expressed as median (interquartile range)

\begin{tabular}{|c|c|c|}
\hline \multirow[t]{2}{*}{ Treatment group } & \multicolumn{2}{|c|}{ Amount of fluid given (ml/kg/day) } \\
\hline & Before ligation & After ligation \\
\hline \multirow{3}{*}{$\begin{array}{l}\text { Regional neonatal unit A } \\
\text { Regional neonatal unit B } \\
\text { Regional neonatal unit C } \\
\text { District general hospitals (D) } \\
\text { Those treated with } \\
\text { indomethacin } \\
\text { Those not treated with } \\
\text { indomethacin }\end{array}$} & $\begin{array}{l}135(120-150) \\
120(100-130)^{*} \\
135(120-150) \\
150(120-150)\end{array}$ & $\begin{array}{l}150(150-165) \\
162(150-175) \\
175(155-175) \\
150(150-175)\end{array}$ \\
\hline & $130(120-150)$ & $160(150-175)$ \\
\hline & $120(105-150)$ & $165(150-175)$ \\
\hline Total & $130(120-150)$ & $162(150-175)$ \\
\hline
\end{tabular}

and was not related to gestational age or birth weight.

After ligation, the median intervals to withdrawal to continuous positive airway pressure (CPAP) and extubation were 7 and 10 days, respectively. Postnatal age at ligation (in those aged 13 days or more) did not influence this (figure). Those in whom the duct was ligated between 9 and 12 days of age, however, had longer median intervals to withdrawal of CPAP (13.5 days, interquartile range (IQR) 7-23), and extubation (20.5 days, IQR 9-25) than those in whom the duct was ligated between 17 and 20 days $(6.5, I Q R \quad 4-10.5$, and $11.5, I Q R$ $5 \cdot 5-17 \cdot 5)$, and those in whom it was ligated when they were more than 25 days of age (7, IQR 2.75-11·75, and 10, IQR 3-15), respectively $(p<0.05)$. Of the three groups in which there were infants older than 17 days, a larger proportion received indomethacin $(p<0.05)$ but there was no difference in the amount of preoperative oxygen supplementation.

No deaths were directly related to the operation, though 15 of the 122 babies (12\%) subsequently died of problems associated with prematurity (table 4). Of 63 infants who required preligation $\mathrm{F}_{\mathrm{I}} \mathrm{O}_{2}$ concentrations of over $0.3,13$ died $(\mathrm{p}<0.05)$.

Two babies had haemorrhages that required re-exploration, but no damage to major vessels was discovered (table 5), and one of these died five days later of rapidly progressive respiratory failure. One infant had a phrenic nerve palsy of uncertain aetiology; segmental lobar collapse affecting particularly the right upper lobe was a serious problem on day 1 . Of the 50 infants who had had cranial ultrasound examinations before

Table 3 Degrees of ventilatory support provided, and intervals between ligation withdrawal of CPAP, and extubation. Values are expressed as median (interquartile range)

\begin{tabular}{|c|c|c|c|c|}
\hline \multirow[t]{2}{*}{ Treatment group } & \multicolumn{2}{|c|}{ Inspiratory oxygen concentration (\%) } & \multicolumn{2}{|c|}{ Intervals (days) from ligation to: } \\
\hline & Before ligation & After ligation & $\begin{array}{l}\text { Withdrawal to } \\
C P A P\end{array}$ & Extubation \\
\hline $\begin{array}{l}\text { Regional neonatal unit A } \\
\text { Regional neonatal unit B } \\
\text { Regional neonatal unit C } \\
\text { District general hospitals (D) } \\
\text { Those treated with indomethacin } \\
\text { Those not treated with indomethacin }\end{array}$ & $\begin{array}{l}35(30-40) \\
25(23-30)^{*} \\
30(25-40) \\
50(30-58) \\
35(30-60) \\
30(25-40)\end{array}$ & $\begin{array}{l}50(39-63) \\
30(25-40)^{* *} \\
50(31-60) \\
68(40-80) \\
43(30-70) \\
45(30-60)\end{array}$ & $\begin{aligned} 7 \cdot 5(4-14) \\
6(2-9)^{* * * *} \\
8(3-14) \\
10(4-18) \\
8(4-17) \\
7(3-14)\end{aligned}$ & $\begin{array}{l}13 \cdot 5(6-23) \\
8 \cdot 5(3-13) \dagger \\
10(4-15) \\
14(5-20) \\
10(5-20) \\
11(4-20)\end{array}$ \\
\hline$\overline{\text { Total }}$ & $30(25-43)$ & $45(30-65)$ & $7(4-15)$ & $10(5-20)$ \\
\hline
\end{tabular}

${ }^{*} p=0.001$ compared with groups $A$ and $D ;{ }^{* *} p=0.001$ compared with groups $A, C$, and $D ;{ }^{* * *} p=0.05$ compared with group $D ;$ and $t p=0.05$ compared with group A. 
30

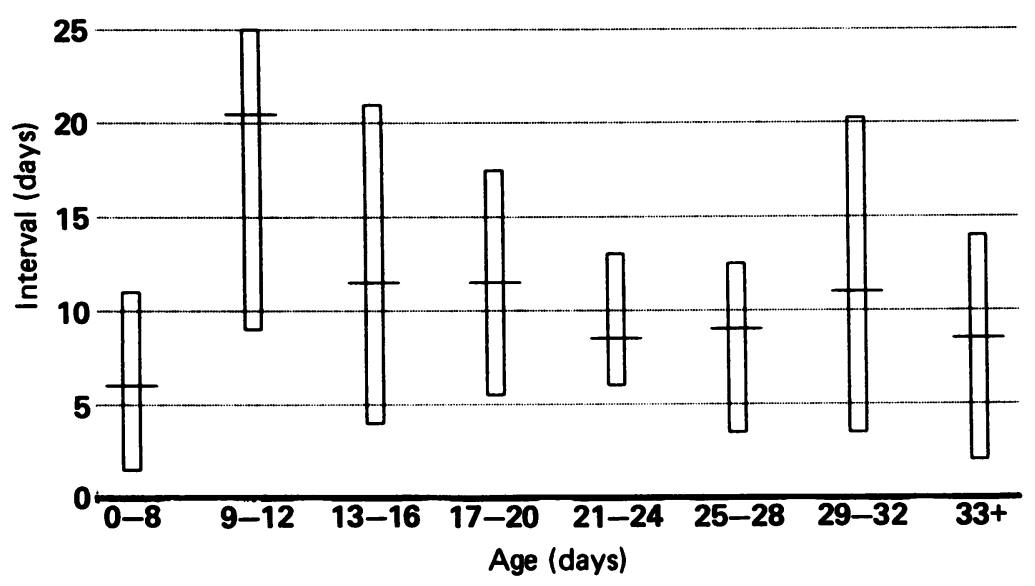

Interval from day of ligation to extubation. The bars indicate the median and interquartile range.
Table 4 Late hospital deaths

\begin{tabular}{ll}
\hline Cause & $\begin{array}{l}\text { No of } \\
\text { infants }\end{array}$ \\
\hline Respiratory failure & 10 \\
Necrotising enterocolitis & 3 \\
Renal failure & 1 \\
Septicaemia & 1 \\
\hline Total & $15 / 122(12 \%)$ \\
\hline
\end{tabular}

Table 5 Complications of duct ligation

\begin{tabular}{lc}
\hline Complication & No of infants \\
\hline Haemorrhage & 2 \\
Stridor & 2 \\
Lobar collapse: & 21 \\
$\quad$ Right & 6 \\
Left & 1 \\
Pneumothorax: & 6 \\
$\quad$ Reft & $37 / 122(30 \%)$ \\
\hline Total & \\
\hline
\end{tabular}

and after ligation only two showed progression, both from normal to grade 1 intraventricular haemorrhage.

No problems were reported concerning the transportation.

\section{Discussion}

This study has shown that day case ligation of the patent ductus arteriosus in preterm infants is safe. There was no mortality associated with the operation or the transport, and morbidity was low. Comparison of the hospital mortality with previous reports $(10-40 \%$, most above $20 \%$ ) indicates that our overall management policy was satisfactory. ${ }^{1} 910$

There were no problems reported concerning transportation despite infants weighing as little as 470 (and more recently $430 \mathrm{~g}$ ) being transfered from hospitals as far as $\mathbf{8 0}$ miles away. The smooth transportation of these infants was facilitated by the excellent network of motorways and $A$ roads linking this city with its neighbours.

The results suggest that neonatal unit $B$, in which fluid restriction was most rigidly practi- sed, achieved the most favourable ventilatory statistics. Though this is in keeping with previous research, we cannot state categorically that this was the sole reason, as many other variables must be taken into account. ${ }^{13} 14$

Those infants who underwent duct ligation between the ages of 9 and 12 days were the slowest to be weaned from ventilatory support; we are uncertain of the reason for this. Among the older infants more had received indomethacin than among the younger, but there were no differences in demographic or ventilatory measurements.

The observed lobar collapse predisposes to a temporary but manageable deterioration in ventilation after ligation. This, however, is not a problem peculiar to preterm infants, and may be seen in patients of all ages after major thoracic and abdominal operations. More intriguing however, is the tendency to collapse of the right upper lobe. The upper lobe bronchus, which is the most dependent major airway in the supine position, may drain inadequately if ciliary function is upset after the anaesthetic, thereby allowing formation of mucous plugs and subsequent collapse.

Northway and Jacob et al have suggested that delay in achieving duct closure may be detrimental, causing progression to bronchopulmonary dysplasia. ${ }^{11} 12$ Duct ligation did, however, control the cardiorespiratory failure with consequent benefits; mechanical ventilation was withdrawn, and the volume of fluid and thus energy was increased to more optimal amounts, so promoting better growth than was encountered preoperatively.

Indomethacin is least successful in closing the ducts of infants with very low birth weights and with severe respiratory distress syndrome requiring assisted ventilation. ${ }^{15}$ Rudd et al showed that in a group of babies weighing less than $1500 \mathrm{~g}$ at birth the incidence of patent ductus arteriosus was $31 \%$. Of these, $87 \%$ initially closed with indomethacin, but $47 \%$ reopened. ${ }^{16}$ Many of the infants treated by day case ligation of the ductus were comparable with this group (116 (95\%) weighed less than $1500 \mathrm{~g}$ at birth) and were thus likely to experience reopening of a ductus that had closed after medical treatment, and unlikely to benefit from a protracted trial of this treatment.

Cotton et al reported that extubation was achieved earlier, and after lower expenditure in patients who had undergone early duct ligation rather than awaiting the result of prolonged medical treatment. ${ }^{17}$ Other authors have supported this view, reporting that the mortality associated with a haemodynamically important patent ductus had risen significantly since the introduction of indomethacin. ${ }^{18}$ They found that results were more satisfactory when early ligation was routine.

Gersony et al, however, reported the results of a multicentre trial that did not confirm these findings. ${ }^{19} \mathrm{~A}$ total of 421 infants were randomised to receive one of three treatment protocols. The first group received indomethacin together with restricted fluids and diuretics as the primary treatment. The second received indomethacin, and the third underwent duct 
ligation only after initial fluid restriction had failed to close the duct. The study showed no significant differences between the length of time that ventilatory support was required by each group, or in the incidence of complications such as bronchopulmonary dysplasia, intracranial haemorrhage, and necrotising enterocolitis. The mortality was also similar.

\section{Conclusion}

Because our patients are a highly selected group we are not in a position to compare medical and surgical treatment of patent ductus arteriosus. Our results do show conclusively, however, that surgical closure can be done safely even after transportation of the ventilated infant to a cardiothoracic centre with appropriate expertise. Where local circumstances are such that the regional cardiothoracic centre is remote from neonatal intensive care facilities, we believe that the policy of day case ligation of the ductus makes most economic use of the time of the surgeon while keeping responsibility for the ventilation and medical care of the infant in the hands of the referring paediatric team.

We suggest that if a preterm infant who is dependent on the ventilator has an arterial duct of sufficient size to merit medical treatment, then failure of this treatment should lead to immediate consideration of surgical ligation.

We thank Professor $M$ Levene of Leeds General Infirmary and Dr P Dear of St James's University Hospital, Leeds, for the valuable advice in the preparation of this report. We thank the Children's Heart Surgery Fund for support.

1 Yeh TF, Luken JA, Thalji A, Raval D, Carr I, Pildes RS. Intravenous indomethacin in premature infants with persistent ductus arteriosus-a double blind trial. $\mathcal{F}$ Pediatr 1981; 98:137-45.
2 Powell ML. Patent ductus arteriosus in premature infants. Med $\mathcal{F}$ Aust 1963;2:58-60.

3 Dudell GG, Gersony WM. Patent ductus arteriosus in neonates with severe respiratory disease. $\mathcal{f}$ Pediatr 1984; 104:915-20.

4 Merritt TA, Harris JP, Roughmann K, et al. Early closure of the patent ductus arteriosus in very low-birth-weight the patent ductus arteriosus in very low-birth-weish

5 Smith DRS, Cook DH, Izukawa T, Trusler GA, Swyer PR, Rowe RD. Surgical management of patent ductus arterioRowe RD. Surgical management of patent ductus arteriosus in newborn in

6 Taylor RL, Grover FL, Harman PK, Escobedo MK, Ramamurthy RS, Trinkle JK. Operative closure of patent ductus arteriosus in premature infants in the neonatal intensive care unit. Am f Surg 1986;152:704-7.

7 Malone PS, Roberts KD, Abrams LD, Jones S, Beasley J. Day-case ligation of patent ductus arteriosus in premature infants. F Pediatr Surg 1987;22:284-5.

8 Satur CMR, Walker DR. The Killingbeck paediatric lung retractor. Ann Thorac Surg 1990;49:491.

9 Palder SB, Schwartz MZ, Tyson KRT, Marr CC. Management of patent ductus arteriosus: a comparison of operative ment of patent ductus arteriosus: a comparison of operative

10 Nagle MG, Peyton MD, Harrison LH, Elkins RC. Ligation of patent ductus arteriosus in very low birthweight infants.
. Peyton Am f Surg 1981;142:681-6.

11 Northway WH Jr. Observations on bronchopulmonary dysplasia. F Pediatr 1979;95:815-8.

12 Jacob J, Gluck L, DiSessa T, et al. The contribution of PDA in the neonate with severe RDS. $\mathcal{F}$ Peditar 1980;96:79-87.

13 Bell EF, Warbuton D, Stonestreet BJ, Oh W. Effect of fluid administration on the development of symptomatic patent ductus arteriosus and congestive heart failure in premature infants. $N$ Engl f Med 1980;302:598-604.

14 Mellander M, Leheup B, Lindstrom DP, et al. Recurrence of symptomatic patent ductus arteriosus in extremely premature infants treated with indomethacin. $\mathcal{F}$ Pediatr 1984;105: $138-43$.

15 Cotton RB, Lindstrom DP, Stahlman MT. Early prediation of symptomatic patent ductus arteriosus from perinatal risk factors: a discriminant analysis model. Acta Paediatr Scand 1981;70:723-7.

16 Rudd $P$, Montanez $P$, Hallidie-Smith $K$, Silverman $M$. Indomethacin treatment for patent ductus arteriosus in
very low birthweight infants: double blind trial. Arch Dis very low birthweight inf

17 Cotton RB, Stahlman MT, Bender HW, Graham TP, Catterton WZ, Kovar I. Randomized trial of early closure of symptomatic patent ductus arteriosus in small preterm infants. $\mathcal{F}$ Pediatr 1978;93:647-51

18 Zerella JT, Spies RJ, Deaver DC, Dailry WJR, Haple DCE, Trump DS. Indomethacin versus immediate ligation in the treatment of 82 newborns with patent ductus arteriosus. f Pediatr Surg 1983;18:835-41.

19 Gersony WM, Peckham GJ, Elisson RC, Miettinen OS, Nadas AS. Effect of indomethacin in premature infants with patent ductus arteriosus: results of a national collaborative study. $\mathcal{F}$ Pediatr 1983;102:895-906. 